\title{
Which characteristics of nursing home residents influence differences in malnutrition prevalence? An international comparison of The Netherlands, Germany and Austria
}

\author{
Noémi C. van Nie-Visser ${ }^{1 *}$, Judith Meijers ${ }^{1}$, Jos Schols ${ }^{1,2}$, Christa Lohrmann ${ }^{3}$, Sabine Bartholomeyczik ${ }^{4}$, \\ Marieke Spreeuwenberg ${ }^{1}$ and Ruud Halfens ${ }^{1}$ \\ ${ }^{1}$ Department of Health Services Research, Faculty of Health, Medicine and Life Sciences, School for Public Health and \\ Primary Care (CAPHRI), Maastricht University, PO Box 616, 6200 MD, Maastricht, The Netherlands \\ ${ }^{2}$ Department of General Practice, Faculty of Health, Medicine and Life Sciences, School for Public Health and Primary Care \\ (CAPHRI), Maastricht University, PO Box 616, 6200 MD, Maastricht, The Netherlands \\ ${ }^{3}$ Institute of Nursing Science, Medical University Graz, Billrothgasse 6, 8010 Graz, Austria \\ ${ }^{4}$ Institute of Nursing Science, University Witten/Herdecke, Stokumerstraße 12, Witten, Germany \\ (Submitted 14 December 2012 - Final revision received 22 August 2013 - Accepted 24 September 2013 - First published online 18 November 2013)
}

\begin{abstract}
Prevalence rates of malnutrition vary considerably internationally, partly due to differences in measurement methodology and instruments. In the present study, the same measurement methodology and instruments were used in The Netherlands, Germany and Austria. The aim of the present study was to investigate whether resident characteristics influence possible differences in malnutrition prevalence between countries. The study followed a cross-sectional, multi-centre design that measured malnutrition in nursing home residents from The Netherlands, Germany and Austria. Resident data were gathered using a standardised questionnaire. Malnutrition was operationalised using BMI, unintentional weight loss and nutritional intake. Data were analysed using an association model. The prevalence rates of malnutrition in The Netherlands, Germany and Austria were 18.3, 20.1 and 22.5\%, respectively. The multivariate generalised estimating equation (GEE) logistic regression analysis showed that sex, age, care dependency, the mean number of diseases and some specific diseases were influencing factors for whether the resident was malnourished or not. The OR of malnutrition in the three countries declined after including the influencing factors resulting from the multivariate GEE analysis. The present study reveals that differences in the prevalence rates of malnutrition in nursing homes in The Netherlands, Germany and Austria are influenced by different resident characteristics. Since other country-related factors could also play an important role in influencing differences in the prevalence rates of malnutrition between the countries (structural and process factors of malnutrition care policy). We recommend the investigation of these factors in future studies.
\end{abstract}

Key words: Malnutrition: Resident characteristics: Nursing homes

Malnutrition is an important and still rather under-recognised problem in health care $^{(1-8)}$. Malnutrition refers to negative deviations from a normal nutritional status, and it has been defined as inadequate nutritional status, undernourishment due to poor dietary intake, poor appetite, muscle wasting and weight loss ${ }^{(9)}$. Elia $^{(10)}$ defined malnutrition as a nutritional condition in which an insufficient or disproportionate intake of energy, protein and other nutrients adversely affects tissue/body form (shape, size and composition) and function, and clinical outcomes.

Malnutrition increases the chance of complications. It worsens the immune function, leading to a higher risk of infections, and impairs wound healing. Moreover, malnutrition impairs the quality of life and increases the length of hospital stay and costs of health care ${ }^{(11-17)}$.

Prevalence rates of malnutrition vary enormously internationally ${ }^{(7,18-22)}$, since in European nursing homes, the prevalence rates of malnutrition have been found to range between 2 and $74 \%{ }^{(23-25)}$. These variations can partly be explained by differences in methodology and instruments used to measure malnutrition, and also resident characteristics can have an influence $^{(26)}$. For instance, age, sex, morbidity and care dependency are related to malnutrition ${ }^{(4,9,19,25-29)}$, as well as to infections $^{(30)}$, physical disabilities ${ }^{(31)}$ and polypharmacy ${ }^{(32,33)}$.

The aim of the present study was to investigate whether resident characteristics influence possible differences in

Abbreviation: LPZ, Landelijke Prevalentiemeting Zorgproblemen (National Prevalence Measurement of Care Problems).

*Corresponding author: N. C. van Nie-Visser, fax +31 4338841 62, email n.vannie@maastrichtuniversity.nl 
malnutrition prevalence between countries, when using the same measurement methodology and instruments. The present hypothesis was that various resident characteristics influence differences in the prevalence rates of malnutrition between The Netherlands, Germany and Austria.

The following research questions will be investigated: (1) What is the prevalence rate of malnutrition in nursing homes in The Netherlands, Germany and Austria? (2) Are the characteristics of malnourished residents different in the three countries? (3) Which resident characteristics influence malnutrition? (4) Is the prevalence of malnutrition in nursing homes in The Netherlands, Germany and Austria different when controlling for the resident characteristics that influence the difference in malnutrition prevalence?

\section{Methods}

For the present study, data were used from the National Prevalence Measurement of Care Problems (in Dutch, Landelijke Prevalentiemeting Zorgproblemen (LPZ)), which is executed annually. Since 2004, the LPZ has been measuring the prevalence, prevention and treatment of malnutrition and quality indicators of nutritional care. It involves an annually conducted measurement in different health care settings (hospitals, long-term care and home care) ${ }^{(34)}$. In 2008, the LPZ measurement expanded internationally to Germany and Austria (LPZ-International). In each country, data are gathered with the same instruments according to the same procedure. These countries conduct the same standardised measurement, supported by the project group of the $\mathrm{LPZ}^{(35)}$. In each country, the coordination of the LPZ is carried out by a national project group led by a national coordinator. The Dutch LPZ project group facilitates each participating country with all documents and a website in their own language to enable them to promote, support and carry out the measurement. Each year, the national coordinators have an international research group meeting to discuss relevant issues and updates concerning possible changes in questionnaires, measurement procedures and cooperations ${ }^{(20,36,37)}$.

\section{Design}

The LPZ uses a cross-sectional, multi-centre design. For the present study, the data of LPZ-International collected in April 2009 and April 2010 in Dutch, German and Austrian nursing homes were analysed.

\section{Instrument}

Data were gathered using a standardised questionnaire at the patient level. As demographic data, age, sex, date of admission, co-morbidity, care dependency, weight, height and unintentional weight loss were measured. Malnutrition was operationalised and validated according to Meijers ${ }^{(38)}$ and Meijers et al. ${ }^{(7,39)}$. Residents were qualified as malnourished if they met one of the following criteria: (1) BMI $\leq 20 \mathrm{~kg} / \mathrm{m}^{2}$ (age $>65$ years); (2) unintentional weight loss (more than $6 \mathrm{~kg}$ in the previous 6 months or more than $3 \mathrm{~kg}$ in the last month); (3) no nutritional intake for $3 \mathrm{~d}$ or reduced intake for more than $10 \mathrm{~d}$ combined with a BMI ranging between 20 and $23.9 \mathrm{~kg} / \mathrm{m}^{2}$ (age $>65$ years).

Care dependency was measured with the Care Dependency Scale ${ }^{(40,41)}$. This scale consists of fifteen items, with a fivepoint Likert scale, and is validated for different settings in several countries ${ }^{(42-45)}$.

Since the original questionnaire and instruction material were in Dutch, these were translated by a professional translator into German. This translation was discussed by the Dutch project group (who spoke also German) with the project group in Germany and Austria until consensus was reached about the translation. The questionnaire was adapted to cultural differences. For instance, the nomenclatures for departments and professions that are present in German and Austrian nursing homes were adjusted to the local situation.

\section{Sample}

All Dutch, German and Austrian nursing homes were invited by (e)mail (including a flyer) and through publications in several professional journals to take part voluntarily in the LPZ measurement.

All residents of the participating nursing homes were invited to participate and included if they (or their legal representatives) gave informed consent. To get a more homogeneous sample, residents were included if they were at least 65 years old. Only those residents who were present at the day of the measurement and who were able to participate in the study were included. Residents were excluded when refusing to participate, not being available at the ward, being comatose or too ill and being terminal. In addition, data from 2009 of residents who participated both in 2009 and 2010 were excluded.

The present study was conducted according to the guidelines laid down in the Declaration of Helsinki, and all procedures involving human subjects/patients were approved by different ethical committees in the different countries. In addition, the LPZ team received ethical approval from the medical ethical committee of the Maastricht University Medical Centre in The Netherlands (oral informed consent). The ethical committee related to the Institute of Nursing Science at Witten/Herdecke University gave its approval for the measurement in Germany and the medical ethical committee of the Medical University Graz approved to carry out the study in Austria (Germany and Austria: written informed consent).

\section{Data collection}

The participating nursing homes chose a coordinator who was responsible for the measurement within the institution. The coordinators were trained collectively by each national LPZ project group on how to organise data collection, and how to use the questionnaire and the specially designed Internet data-entry program. Subsequently, all the coordinators trained the health care professionals who would perform the data collection. For this purpose, the coordinators received a protocol and training package from the Dutch project 
group to support them in training the health care professionals.

The assessment of the residents took place always by pairs of health care professionals (nurses, dietitians or doctors), one working on the resident's ward and one independent observer from another ward to enhance reliability.

\section{Data analyses}

Statistical analyses were performed using SPSS version 19 (SPSS, Inc.). $\chi^{2}$ tests, Student's $t$ test or ANOVA (with post hoc analyses using the Bonferroni method) and OR were used to describe the differences in (malnourished) resident characteristics between The Netherlands, Germany and Austria. Resident characteristics involved variables such as age, sex, length of stay, type and number of diseases and care dependency. Univariate logistic regression analyses were performed to describe the relationship of each baseline independent variable with the prevalence of malnutrition. Independent variables were country $(0=$ The Netherlands, $1=$ Germany and $2=$ Austria) and resident characteristics such as age, sex, length of stay, type and number of diseases and care dependency. For identifying differences in malnutrition prevalence between the countries, $P$ values were based on two-sided tests, and the cut-off point for statistical significance was set at $P<0.05$.

A univariate logistic generalised estimating equation (GEE) regression analysis was performed to estimate the OR of countries regarding the prevalence of malnutrition. The dependent variable was malnourished/not malnourished; the independent variables were two dummy variables indicating country (with The Netherlands as the reference category). GEE analysis corrects for the dependency of observations of individuals within institutions by adding a 'within-subject correlation structure' to the regression model. An exchangeable correlation structure was used, which means that correlations between individuals within the institutions are assumed to be the same. For building the association model, all variables that were significantly different between the three countries and related to malnutrition (both with $P<0 \cdot 10$ ) were seen as possible influencing variables (or confounders) in the GEE analyses. For that purpose, in the multivariate logistic regression analysis, all factors that were related to country and malnutrition difference (with $P<0 \cdot 10$ ) were added to the univariate model step by step so that the mean of both regression coefficients of the dummy variables for country changed. Only the covariates that led to a significant change (more than $10 \%$ of the regression coefficients) were included ${ }^{(46)}$.

In the final multivariate model (corrected model), the OR of malnutrition in nursing homes in The Netherlands, Germany and Austria were estimated when controlling for the influencing resident characteristics. In this analysis, we focused on the change in the OR of malnutrition between the countries in the uncorrected model (univariate, without controlling for influencing resident characteristics) compared with the corrected model (multivariate, controlling for the observed influencing resident characteristics, see Table 5). Before the multivariate analysis, data were assessed for congruence with regression assumptions.

\section{Results}

\section{Response}

In the present study, 214 nursing homes with 19876 residents were included in the analyses: 133 nursing homes from The Netherlands ( $n$ 14123), sixty-one nursing homes from Germany ( $n$ 3973) and twenty nursing homes from Austria ( $n$ 1780). The response rate was significantly higher in The Netherlands (92.9\%) than in Germany (82.9\%) and Austria $(80.8 \%)$. The reasons for not taking part in the measurement were refusing to participate $(64.3 \%)$, not being available at the ward (27\%), being comatose or too ill (5.7\%) and being terminal $(3 \cdot 0 \%)$.

\section{Resident characteristics}

In Table 1, the characteristics of the included residents are shown separately for The Netherlands, Germany and Austria. Dutch residents were more often male, had a shorter mean length of stay, were less dependent of care and had fewer diseases than residents in Germany and Austria.

The most prevalent diseases in all the three countries were dementia ( $42 \cdot 1 \%$ in The Netherlands, $55.2 \%$ in Germany and $60.8 \%$ in Austria), CVD ( $41.2 \%$ in The Netherlands, $70.0 \%$ in Germany and $59.0 \%$ in Austria) and motor disorders (27.0\% in The Netherlands, $41.9 \%$ in Germany and $41.7 \%$ in Austria).

\section{Malnutrition prevalence}

The prevalence of malnutrition also differed significantly between the countries $(P<0 \cdot 05$; Table 2$)$.

In Germany and Austria, the prevalence was somewhat higher than in The Netherlands $(20.0$ and $22.7 \% \mathrm{v} .18 .0 \%$, respectively).

\section{Relationship between resident characteristics and malnutrition}

Table 3 shows the prevalence of the different characteristics for the malnourished and not malnourished residents. Malnourished residents had more diseases and were older, more care dependent and more often female than those not malnourished. Furthermore, a significant difference was found between the malnourished and not malnourished residents concerning the type of prevalent diseases such as infectious disease, cancer, diabetes mellitus, blood disease, dementia, diseases of the digestive tract, injury resulting from accidents and total hip replacement. No significant difference was found in the length of stay.

To calculate which resident characteristics influenced the differences found in the prevalence rates of malnutrition between the countries, the factors that showed a significant difference between the countries and between the malnourished 
Table 1. Resident characteristics, number and kind of disease, care dependency and malnutrition prevalence (Mean values and standard deviations; percentages)

\begin{tabular}{|c|c|c|c|c|c|c|c|}
\hline & \multicolumn{2}{|c|}{$\begin{array}{l}\text { The } \\
\text { Netherlands }\end{array}$} & \multicolumn{2}{|c|}{ Germany } & \multicolumn{2}{|c|}{ Austria } & \multirow[b]{2}{*}{$P$} \\
\hline & $n$ & $\%$ & $n$ & $\%$ & $n$ & $\%$ & \\
\hline Nursing homes & 133 & $62 \cdot 2$ & 61 & 28.5 & 20 & $9 \cdot 3$ & \\
\hline Residents & 14123 & $71 \cdot 0$ & 3973 & $20 \cdot 0$ & 1780 & $9 \cdot 0$ & \\
\hline \multicolumn{7}{|l|}{ Sex } & \multirow[t]{3}{*}{$<0.0001^{*} \dagger \ddagger$} \\
\hline Male & 3717 & $26 \cdot 3$ & 868 & 21.8 & 255 & $14 \cdot 3$ & \\
\hline Female & 10409 & $73 \cdot 7$ & 3105 & $78 \cdot 2$ & 1525 & 85.7 & \\
\hline \multicolumn{7}{|l|}{ Age (years) } & \multirow[t]{3}{*}{$<0.0001^{*} \dagger \ddagger$} \\
\hline Mean & 84 & & 83 & & 85 & & \\
\hline $\mathrm{SD}$ & 7 & & 8 & & 8 & & \\
\hline \multicolumn{7}{|l|}{ Age categories } & \multirow[t]{4}{*}{$<0.0001$} \\
\hline $65-74$ years & 1311 & $9 \cdot 3$ & 634 & $16 \cdot 0$ & 187 & 10.5 & \\
\hline $75-84$ years & 5432 & 38.5 & 1396 & $35 \cdot 1$ & 557 & 31.3 & \\
\hline$\geq 85$ years & 7383 & $52 \cdot 3$ & 1943 & $48 \cdot 9$ & 1036 & $58 \cdot 2$ & \\
\hline \multicolumn{7}{|l|}{ Length of stay (d) } & \multirow[t]{4}{*}{$<0.0001^{\star} \dagger \ddagger$} \\
\hline Median & 631 & & 767 & & 694 & & \\
\hline Mean & 1017 & & 1407 & & 1195 & & \\
\hline SD & 1463 & & 2129 & & 1953 & & \\
\hline \multicolumn{7}{|l|}{ Care dependency } & \multirow[t]{3}{*}{$<0.0001^{*} \dagger \ddagger$} \\
\hline Dependent & 8341 & 59.1 & 2927 & 73.7 & 1431 & $80 \cdot 4$ & \\
\hline Independent & 5783 & $40 \cdot 9$ & 1045 & $26 \cdot 3$ & 349 & $19 \cdot 6$ & \\
\hline \multicolumn{8}{|l|}{ Diseases } \\
\hline Infectious disease & 173 & 1.2 & 72 & 1.8 & 58 & $3 \cdot 3$ & $<0.0001^{*} \dagger \ddagger$ \\
\hline Cancer & 996 & 7.1 & 325 & $8 \cdot 2$ & 148 & 8.3 & $0.016^{\star}$ \\
\hline Endocrine/nutritional/metabolic disease & 645 & 4.6 & 497 & $12 \cdot 5$ & 230 & $12 \cdot 9$ & $<0.0001^{*} \dagger$ \\
\hline Diabetes mellitus & 2554 & $18 \cdot 1$ & 1103 & $27 \cdot 8$ & 329 & 18.5 & $<0.0001^{*} \ddagger$ \\
\hline Blood disease & 416 & 2.9 & 176 & 4.4 & 87 & 4.9 & $<0.0001^{*} \dagger$ \\
\hline Psychological disorder & 1734 & $12 \cdot 3$ & 1269 & 31.9 & 372 & $20 \cdot 9$ & $<0.0001^{*} \dagger \ddagger$ \\
\hline Dementia & 5943 & $42 \cdot 1$ & 2192 & $55 \cdot 2$ & 1082 & $60 \cdot 8$ & $<0.0001^{*} \dagger \ddagger$ \\
\hline Nervous system disorder & 1262 & 8.9 & 617 & $15 \cdot 5$ & 264 & $14 \cdot 8$ & $<0.0001^{*} \dagger$ \\
\hline Eye/ear disorder & 2728 & $19 \cdot 3$ & 552 & $13 \cdot 9$ & 330 & $18 \cdot 5$ & $<0.0001^{*} \ddagger$ \\
\hline Spinal cord lesion/paraplegia & 29 & 0.2 & 10 & 0.3 & 8 & 0.4 & 0.132 \\
\hline CVD & 5819 & 41.2 & 2782 & $70 \cdot 0$ & 1051 & $59 \cdot 0$ & $<0.0001^{*} \dagger \ddagger$ \\
\hline CVA/hemiparesis & 2677 & $19 \cdot 0$ & 714 & $18 \cdot 0$ & 319 & $17 \cdot 9$ & 0.265 \\
\hline Respiratory disorder/disease & 1966 & 13.9 & 402 & $10 \cdot 1$ & 173 & $9 \cdot 7$ & $<0.0001^{*} \dagger$ \\
\hline Diseases of the digestive tract & 1610 & 11.4 & 1101 & $27 \cdot 7$ & 367 & $20 \cdot 6$ & $<0.0001^{*} \dagger \ddagger$ \\
\hline Disorder/disease of kidney/urinary tract & 1658 & 11.7 & 1029 & $25 \cdot 9$ & 379 & $21 \cdot 3$ & $<0.0001^{*} \dagger \ddagger$ \\
\hline Skin disorder & 903 & 6.4 & 249 & $6 \cdot 3$ & 133 & 7.5 & 0.187 \\
\hline Motor disorder & 3814 & $27 \cdot 0$ & 1663 & 41.9 & 742 & $41 \cdot 7$ & $<0.0001^{*} \dagger$ \\
\hline Congenital disorders & 162 & 1.1 & 101 & 2.5 & 49 & $2 \cdot 8$ & $<0.0001^{*} \dagger$ \\
\hline Injury resulting from accidents & 493 & 3.5 & 202 & $5 \cdot 1$ & 153 & 8.6 & $<0.0001^{\star} \dagger \ddagger$ \\
\hline Total hip replacement & 769 & 5.4 & 222 & $5 \cdot 6$ & 128 & $7 \cdot 2$ & $0.011 \dagger \ddagger$ \\
\hline Other non-specified diseases & 1116 & $7 \cdot 9$ & 452 & $11 \cdot 4$ & 208 & $11 \cdot 6$ & $<0.0001^{*} \dagger$ \\
\hline Prevalent diseases & & & \multirow{3}{*}{\multicolumn{2}{|c|}{$\begin{array}{l}3.87 \\
1.68\end{array}$}} & & & $<0.0001^{*} \dagger \ddagger$ \\
\hline Mean & \multirow{2}{*}{\multicolumn{2}{|c|}{$\begin{array}{l}2 \cdot 6 \\
1.57\end{array}$}} & & & \multirow{2}{*}{\multicolumn{2}{|c|}{$\begin{array}{l}3.64 \\
1.98\end{array}$}} & \\
\hline SD & & & & & & & \\
\hline
\end{tabular}

CVA, cerebrovascular accident.

* Values were significantly different between The Netherlands and Germany.

†Values were significantly different between The Netherlands and Austria.

$\ddagger$ Values were significantly different between Germany and Austria.

and not malnourished residents $(P<0 \cdot 1)$ were incorporated in a multivariate GEE analysis.

\section{Possible influencing variables (GEE analyses and association model)}

Tables 1 and 3 show that sex, age, age categories, mean number of diseases and care dependency, as well as infectious disease, cancer, diabetes mellitus, blood disease, dementia, CVD, respiratory disease, diseases of the digestive tract, motor disorder, injury resulting from accidents, total hip replacement or other non-specified diseases were possible confounders or influencing variables $(P<0 \cdot 01)$. After entering these variables step by step in the univariate model, in the final multivariate model (corrected model; Table 4) the variables care dependency, CVD, diseases of the digestive tract, age, dementia, diabetes mellitus, sex, mean number of diseases, respiratory disease and other non-specified diseases were included as influencing variables for the difference in malnutrition prevalence in the three countries. The two most influencing resident characteristics (confounders) were care dependency and CVD. The confounders resulting from the analyses influence the OR of countries. 
Table 2. Prevalence of malnutrition

(Number of prevalence of malnutrition and percentages; odds ratios and $95 \%$ confidence intervals)

\begin{tabular}{|c|c|c|c|c|c|}
\hline & \multicolumn{2}{|c|}{$\begin{array}{l}\text { Prevalence of } \\
\text { malnutrition }\end{array}$} & \multirow[b]{2}{*}{$P$} & \multirow[b]{2}{*}{ OR } & \multirow[b]{2}{*}{$95 \% \mathrm{Cl}$} \\
\hline & $n$ & $\%$ & & & \\
\hline Total $(n$ 19771) & 3729 & $18 \cdot 9$ & & & \\
\hline $\begin{array}{l}\text { The Netherlands } \\
\qquad(n 14021)^{*}\end{array}$ & 2530 & $18 \cdot 0$ & & & \\
\hline Germany (n 3972) & 795 & $20 \cdot 0$ & 0.05 & $1 \cdot 137$ & $1.040,1.242$ \\
\hline Austria $(n 1778)$ & 404 & 22.7 & 0.0001 & 1.335 & $1.186,1.504$ \\
\hline
\end{tabular}

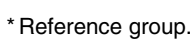

After controlling for these variables in the final multivariate model (corrected model), the OR of malnutrition difference between the three countries declined. The OR of malnutrition prevalence declined when comparing the univariate model (without controlling for predictive resident characteristics) with the multivariate model (controlling for influencing resident characteristics) (see Table 4) between the countries (see Table 5). The OR of malnutrition between The Netherlands and Germany declined from 1.137 to 1.065 (Odds ratios and $95 \%$ confidence intervals)
$(P=0 \cdot 201)$. The OR of malnutrition between The Netherlands and Austria declined from 1.335 to $1.085(P=0.213)$. After controlling for the influencing resident characteristics (confounders), there were no differences any more; the OR declined to 1 , implying that the differences in the prevalence rates of malnutrition declined.

The difference was not significant any more between The Netherlands and Germany and Austria when controlling for these influencing resident characteristics.

\section{Discussion}

The present unique large-scale study explored whether resident characteristics influence possible differences in malnutrition prevalence between The Netherlands, Germany and Austria, when using the same measurement methodology and instrument.

The prevalence of malnutrition differed significantly between the countries. The highest prevalence was found in Austria (22.7\%, The Netherlands $18.0 \%$ and Germany $20.0 \%$ ). These prevalence findings are within the range of earlier internationally reported malnutrition prevalence rates. Data collected by the Nutrition Day survey showed a malnutrition prevalence of $16.7 \%$ in nursing home residents

Table 3. Patients with malnutrition $(\mathrm{M}+)$ /without malnutrition $(\mathrm{M}-)$ and patient characteristics

\begin{tabular}{|c|c|c|c|c|c|}
\hline & $M+(n$ 3729) & $M-(n 16042)$ & $P$ & OR & $95 \% \mathrm{Cl}$ \\
\hline $\operatorname{Sex}(\%)$ & & & $<0.0001$ & 1.420 & $1.306,1.543$ \\
\hline Male & $19 \cdot 4$ & 25.5 & & & \\
\hline Female & $80 \cdot 6$ & 74.5 & & & \\
\hline Mean age (years) & $85 \cdot 1$ & 84.0 & $<0.0001$ & 1.026 & $1.021,1.031$ \\
\hline Age categories (\%) & & & $<0.0001$ & $1 \cdot 221$ & $1 \cdot 156,1.289$ \\
\hline $65-74$ years & 8.6 & $11 \cdot 2$ & & & \\
\hline $75-84$ years & $34 \cdot 1$ & $37 \cdot 8$ & & & \\
\hline$\geq 85$ years & $57 \cdot 2$ & $51 \cdot 0$ & & & \\
\hline Mean length of stay (days) & 1143 & 1184 & $0 \cdot 101$ & 1 & $1.000,1.000$ \\
\hline Care dependency (\%) & & & $<0.0001$ & $2 \cdot 190$ & $2 \cdot 016,2 \cdot 379$ \\
\hline Dependent & $22 \cdot 8$ & 11.9 & & & \\
\hline Independent & $77 \cdot 2$ & $88 \cdot 1$ & & & \\
\hline \multicolumn{6}{|l|}{ Diseases (\%) } \\
\hline Infectious disease & 1.9 & 1.4 & 0.026 & 1.354 & $1.036,1.768$ \\
\hline Cancer & 8.5 & $7 \cdot 1$ & 0.003 & 1.214 & $1.066,1.382$ \\
\hline Endocrine/nutritional/metabolic disease & 7.5 & $6 \cdot 8$ & 0.136 & 1.109 & $0.968,1.272$ \\
\hline Diabetes mellitus & 14.7 & $21 \cdot 4$ & $<0.0001$ & 0.633 & $0.574,0.699$ \\
\hline Blood disease & $4 \cdot 0$ & 3.3 & 0.027 & 1.231 & $1.024,1.482$ \\
\hline Psychological disorder & $16 \cdot 3$ & $17 \cdot 1$ & 0.253 & 0.946 & $0.859,1.041$ \\
\hline Dementia & $56 \cdot 3$ & $44 \cdot 1$ & $<0.0001$ & 1.632 & $1.519,1.754$ \\
\hline Nervous system disorder & $11 \cdot 2$ & $10 \cdot 7$ & 0.402 & 1.050 & $0.935,1.176$ \\
\hline Eye/ear disorder & $17 \cdot 8$ & $18 \cdot 3$ & 0.491 & 0.968 & $0.882,1.062$ \\
\hline CVD & 44.9 & $49 \cdot 6$ & $<0.0001$ & 0.830 & $0.773,0.892$ \\
\hline CVA/hemiparesis & $17 \cdot 9$ & $18 \cdot 8$ & 0.176 & 0.938 & $0.855,1.029$ \\
\hline Respiratory disorder/disease & $14 \cdot 1$ & $12 \cdot 5$ & 0.011 & 1.145 & $1.032,1.269$ \\
\hline Diseases of the digestive tract & 18.5 & $14 \cdot 8$ & $<0.0001$ & 1.303 & $1.187,1.431$ \\
\hline Disease of kidney/urinary tract & $15 \cdot 6$ & $15 \cdot 4$ & 0.747 & 1.016 & $0.921,1 \cdot 121$ \\
\hline Skin disorder & $6 \cdot 3$ & 6.5 & 0.574 & 0.959 & $0.828,1.110$ \\
\hline Motor disorder & 33.0 & $30 \cdot 9$ & 0.015 & 1.099 & $1.019,1.186$ \\
\hline Congenital disorders & 1.4 & 1.6 & 0.323 & 0.858 & $0.634,1.162$ \\
\hline Injury resulting from accidents & $5 \cdot 7$ & 4.0 & $<0.0001$ & 1.458 & $1.242,1.711$ \\
\hline Total hip replacement & $6 \cdot 5$ & 5.4 & 0.012 & $1 \cdot 207$ & $1.042,1.399$ \\
\hline Other non-specified diseases & $10 \cdot 4$ & 8.6 & 0.001 & 1.207 & $1.042,1.399$ \\
\hline Mean number of prevalent diseases & 3.02 & 2.90 & $<0.0001$ & 1.031 & $1.011,1.051$ \\
\hline
\end{tabular}

CVA, cerebrovascular accident. 
Table 4. Generalised estimating equation (GEE) - association model

\begin{tabular}{lcccccc}
\hline & $\mathrm{B} 1{ }^{*}$ & $\mathrm{~B} 2 \dagger$ & $95 \% \mathrm{Cl}(\mathrm{B} 1)$ & $95 \% \mathrm{Cl}(\mathrm{B} 2)$ & $P(\mathrm{~B} 1)$ & $P(\mathrm{~B} 2)$ \\
\hline Uncorrected model $)$ & -0.289 & -0.128 & $-0.408,-0.170$ & $-0.217,-0.039$ & 0.00 & 0.05 \\
Corrected model§ & -0.079 & -0.063 & $-0.204,0.046$ & $-0.161,0.034$ & 0.213 & 0.201 \\
\hline
\end{tabular}

${ }^{*} \mathrm{~B} 1$, comparing Austria with The Netherlands.

†B2, comparing Germany with The Netherlands.

$\ddagger$ Variables in model: country (The Netherlands as a reference group, Germany and Austria) and malnutrition prevalence.

$\S$ Corrected for variables: care dependency, age, sex, mean number of diseases and specific diseases (CVD, disease of the digestive tract, dementia, diabetes mellitus, respiratory disorder and other non-specified diseases).

in Germany ${ }^{(6)}$. Furthermore, a study by Tannen et $a l .{ }^{(47)}$ has shown comparable rates $(15 \cdot 1 \%)$ collected in German nursing homes, and another study has shown the same rates (15.7\%) in Austrian hospitals ${ }^{(48)}$. A study in different aged care residents in Australia has shown a much higher prevalence rate. The prevalence of malnutrition across these facilities varied from $31 \cdot 8$ to $72 \cdot 1 \%{ }^{(19)}$. In interpreting the differences between these studies, it must be realised that each study uses its own methodology as well as definition and operationalisation of malnutrition.

Resident characteristics that were both related to country and malnutrition were seen as possible influencing variables (or confounders) in the GEE analyses. Being female, being older, having more diseases and having diseases such as CVD, disease of the digestive tract, dementia, diabetes mellitus, respiratory disorder and other non-specified diseases influence the chance of getting malnourished.

The present study revealed that the two largest confounders are being more care dependent and having a CVD. This finding is confirmed in other studies showing that malnourished residents are more care dependent. Other studies confirm the present findings on the relationship between malnutrition and $\mathrm{CVD}^{(49,50)}$. Furthermore, the remaining confounders found in the GEE analyses have also been indicated by other studies. Residents have more often several diseases such as disease of the digestive tract and respiratory disorder $^{(31,51)}$. Other studies have shown that women are more at risk of getting malnourished ${ }^{(52)}$. Gaskill et al. ${ }^{(19)}$ found a relationship between malnutrition and an increased age and

Table 5. OR of malnutrition in The Netherlands, Germany and Austria, controlling for influencing resident characteristics

(Odds ratios and $95 \%$ confidence intervals)

\begin{tabular}{|c|c|c|c|}
\hline & $P$ & OR & $95 \% \mathrm{Cl}$ \\
\hline \multicolumn{4}{|l|}{ Univariate } \\
\hline \multicolumn{4}{|c|}{ The Netherlands* } \\
\hline Germany & 0.05 & $1 \cdot 137$ & $1.040-1.242$ \\
\hline Austria & 0.001 & 1.335 & $1 \cdot 186-1.504$ \\
\hline \multicolumn{4}{|l|}{ Multivariate† } \\
\hline \multicolumn{4}{|c|}{ The Netherlands } \\
\hline Germany & 0.201 & 1.065 & $0.967-1.174$ \\
\hline Austria & 0.213 & 1.083 & $0.955-1 \cdot 227$ \\
\hline
\end{tabular}

high level of care needs. Suominen et al. ${ }^{(51)}$ described similar patient-related factors that explain malnutrition in nursing home residents in Finland. Their logistic regression analyses have shown that impaired functioning, swallowing difficulties, dementia and constipation are associated with being malnourished $^{(51)}$. This is also in line with the present findings. Although the present study shows that resident characteristics influence differences in the prevalence rates of malnutrition between countries, it has never been studied using the same method and definition on a large scale in different countries.

There was no significant difference between The Netherlands, Germany and Austria after controlling for these influencing variables. In addition to resident characteristics, other influencing variables could also play a role in the difference in malnutrition prevalence between countries. Possible influencing variables could be differences in health care structure as nutritional care policies (e.g. nutritional screening policy, implementation of a nutritional care protocol/ guideline, the policy of discussing malnourished residents in a multidisciplinary team) and care processes (e.g. preventive and treatment measures used). A study by Meesterberends et $a l^{(53)}$ has revealed that six factors, including resident-related, nursing-related and structure-related factors, explain the differences in the incidence rates of pressure ulcer between nursing homes in The Netherlands and Germany. Future studies must be performed to assess the specific contribution of these structural and process factors to differences in the prevalence rates of malnutrition in different countries.

\section{Limitations}

In the present study, data from three countries were analysed with different sample sizes. While the institutions participated voluntarily, no information was available about the degree of representativeness of the samples. However, to date, no other studies with such a large number of patients have been published.

Since there is no globally accepted 'gold' standard for malnutrition, we based the present study on a definition that meets those factors for which consensus exists ${ }^{(39)}$.

Finally, it might be possible that more and other resident characteristics that were not taken into account in the present study are likely to influence the risk of getting malnourished. Therefore, we assume that structural and process factors of malnutrition could also play a role. 


\section{Conclusion}

Malnutrition is still a considerable problem; about $20 \%$ of all nursing home residents in the present study were malnourished. There are differences between countries, which can be explained by resident characteristics. Since other country-related factors such as structural and process factors of malnutrition could also play an important role in influencing differences in the prevalence rates of malnutrition between countries, we recommend the investigation of these factors in future studies.

\section{Acknowledgements}

We thank Nutricia Advanced Medical Nutrition for providing an unrestricted grant. Nutricia Advanced Medical Nutrition had no role in the design, analysis or writing of this article.

N. v. N., J. M., J. S. and R. H. contributed to the design of the study. N. v. N., J. M., J. S., C. L., S. B. and R. H. helped in the data collection. N. v. N, J. M., M. S. and R. H. conducted the data analyses N. v. N., J. M., J. S., C. L., M. S. and R. H. wrote the manuscript. M. S. provided significant advice and consultation concerning statistical issues. N. v. N, J. M., J. S., C. L., M. S. and R. H. approved the final manuscript.

There are no conflicts of interest to report.

\section{References}

1. Waitzberg DL, Caiaffa WT \& Correia MI (2001) Hospital malnutrition: the Brazilian National Survey (IBRANUTRI): a study of 4000 patients. Nutrition 17, 573-580.

2. Correia IM \& Campos ACL (2003) The prevalence of hospital malnutrition in Latin America: the multicenter ELAN study. Nutrition 19, 823-825.

3. Kruizenga HM, Wierdsma NJ, Van Bokhorst-de van der Schueren MAE, et al. (2003) Screening of nutritional status in The Netherlands. Clin Nutr 22, 147-152.

4. Stratton RJ, Green CJ \& Elia M (2003) Disease-Related Malnutrition: An Evidence-Based Approach To Treatment, 1st ed. Cambridge, MA: CABI Publishing.

5. Pirlich M, Schutz T, Norman K, et al. (2006) The German hospital malnutrition study. Clin Nutr 25, 563-572.

6. Valentini L, Schindler K, Schlaffer R, et al. (2009) The first Nutrition Day in nursing homes: participation may improve malnutrition awareness. Clin Nutr 28, 109-116.

7. Meijers JMM, Schols JMGA, Van Bokhorst-de van der Schueren MAE, et al. (2009b) Malnutrition prevalence in the Netherlands: results of the annual Dutch National Prevalence Measurement of Care. Br J Nutr 101, 417-423.

8. Vanderwee K, Clays E, Bocquaert I, et al. (2010) Malnutrition and associated factors in elderly hospital patients: a Belgian cross-sectional, multi-centre study. Clin Nutr 29, 469-476.

9. Chen CC, Schilling LS \& Lyder CH (2001) A concept analysis of malnutrition in the elderly. J Adv Nurs 36, 131-142.

10. Elia M (2000) Guidelines for Detection and Management of Malnutrition. Maidenhead: Malnutrition Advisory Group (MAG), Standing Committee of BAPEN.

11. Green CJ (1999) Existence, causes and consequences of disease-related malnutrition in the hospital and the community, and clinical and financial benefits of nutritional intervention. Clin Nutr 18, 3-28.

12. Elia M, Stratton R, Russel C, et al. (2005) The Costs of Disease-Related Malnutrition in the UK and Economic
Considerations for the Use of Oral Nutritional Supplements (ONS) in Adults. Redditch: BAPEN.

13. Russel C (2007) The impact of malnutrition on healthcare costs and economic considerations for the use of oral nutritional supplements. Clin Nutr Suppl 2, 25-32.

14. Arvanitakis M, Beck A, Coppens P, et al. (2008) Nutrition in care homes and homecare: how to implement adequate strategies (report of the Brussel Forum (22-23 November 2007)). Clin Nutr Suppl 2, 25-32.

15. Norman K, Pichard C, Lochs H, et al. (2008) Prognostic impact of disease-related malnutrition. Clin Nutr 27, 481-488.

16. Banks M, Bauer J, Graves N, et al. (2010) Malnutrition and pressure ulcer risk in adults in Australian heath care facilities. Nutrition 26, 896-901.

17. Meijers JMM, Halfens RJG, Wilson L, et al. (2012) Estimating the cost associated with malnutrition in Dutch nursing homes. Clin Nutr 31, 65-68.

18. Donini LM, De Felice MR \& Cannella C (2007) Nutritional status determinants and cognition in the elderly. Arch Gerontol Geriatr 44, Suppl. 1, 143-153.

19. Gaskill D, Black LJ, Isenring EA, et al. (2008) Malnutrition prevalence and nutrition issues in residential aged care facilities. Australas J Ageing 27, 189-194.

20. Bartholomeyczik S, Reuther S, Luft L, et al. (2010) Prävalenz von Mangelernährung, Maßnahmen und Qualitätsindikatoren in deutschen Altenpflegeheimen - erste Ergebnisse einer landesweiten Pilotstudie (Prevalence of malnutrition, intervention and quality indicators in German nursing homes - first results of a nationwide pilot study). Gesundbeitswesen 72, 1-7.

21. Kaiser MJ, Bauer JM, Rämsch C, et al. (2010) Frequency of malnutrition in older adults: a multinational perspective using the mini nutritional assessment. J Am Geriatr Soc 58, $1734-1738$.

22. Westergren A, Lindholm C, Axelsson C, et al. (2008) Prevalence of eating difficulties and malnutrition among persons within hospital care and special accommodations. $J$ Nutr Health Aging 12, 39-43.

23. Volkert D, Kreuel K, Heseker H, et al. (2004) Energy and nutrient intake of young-old, old-old and very-old elderly in Germany. Clin Nutr 58, 1190-1200.

24. Pauly L, Stehle P \& Volkert D (2007) Nutritional situation of elderly nursing home residents. Z Gerontol Geriatr 40, 3-12.

25. Meijers JMM, Halfens RJG, Van Bokhorst-de van der Schueren MAE, et al. (2009a) Malnutrition in Dutch healthcare: prevalence, prevention, treatment and quality indicators. Nutrition 25, 512-519.

26. Westergren A, Wann-Hansson C, Bergh Börgdal E, et al. (2009) Malnutrition prevalence and precision in nutritional care differed in relation to hospital volume - cross-sectional survey. Nutrition $\mathbf{8}, 20$.

27. Lewis EJ \& Stacey JB (1990) Nutritional assessment in the elderly. In Geriatric Nutrition, pp. 73-87 [JE Morley, Z Glick and LZ Rubenstein, editors]. New York: Raven Press.

28. Perissinotto E, Pisent C, Sergi G, et al. (2002) Anthropometric measurements in the elderly, age and gender differences. $\mathrm{Br}$ J Nutr 87, 177-186.

29. Aliabadi M, Kimiagar M, Ghayour-Mobarhan M, et al. (2008) Prevalence of malnutrition in free living elderly people in Iran: a cross-sectional study. Asia Pac J Clin Nutr 17, $285-289$.

30. Vitale E (2011) An evaluation of the association of malnutrition with nosocomial infections in elderly patients. Immunopharmacol Immunotoxicol (epublication ahead of print version). 
31. Oliveira MRM, Fogaça KCP \& Leandro-Merhi VA (2009) Nutritional status and functional capacity of hospitalized elderly. Nutr J 8, 54 .

32. Heuberger RA \& Caudell K (2011) Polypharmacy and nutritional status in older adults. A cross-sectional study. Drug Aging 28, 315-323.

33. Jyrkkä J, Mursu J, Enlund H, et al. (2012) Polypharmacy and nutritional status in elderly people. Curr Opin Clin Nutr Metab Care 15, 1-6.

34. Halfens RJG, Meesterberends E \& Meijers JMM, et al. (2011) Rapportage resultaten: Landelijke Prevalentiemeting Zorgproblemen 2011 Annual Report. Maastricht University, Maastricht, The Netherlands.

35. Nie van NC, Schols MGA, Lohrmann C, et al. (2013) An international prevalence measurement of care problems: study design. J Adv Nurs 69, e18-e29.

36. Schönherr S, Halfens R, Meijers J, et al. (2012) Structural and process indicators of nutritional care: a comparison between Austrian hospitals and nursing homes. Nutrition 28, $868-873$

37. Nie van NC, Meijers JMM, Schols MGA, et al. (2011) Comparing quality of nutritional care in Dutch and German nursing homes. J Clin Nurs 20, 2501-2508.

38. Meijers JMM (2009) Awareness of malnutrition in healthcare. The Dutch perspective PhD Thesis, Maastricht University, School for Public Health and Primary Care, Maastricht, The Netherlands.

39. Meijers JMM, Van Bokhorst-de van der Schueren MAE, Schols JMGA, et al. (2010) Defining malnutrition: mission or mission impossible. Nutrition 26, 432-440.

40. Dijkstra A (1998) Care dependency - an assessment instrument for use in long term care facilities PhD Thesis, Groningen: Rijksuniveristeit Groningen.

41. Lohrmann C (2003) Pflegeabhängigkeitsskala: ein Einschätzungsinstrument für Heime und Klinieken - Eine methodologische Studie PhD Thesis, Berlin Center of Humanities and Health Science, Charite-Universitätsmedizin, Berlin, Germany.

42. Dijkstra A, Buist G, Moorer P, et al. (1999) Construct validity of the Nursing Care Dependency Scale. J Clin Nurs 8, $380-388$
43. Dijkstra A, Brown L, Havens B, et al. (2000) An international psychometric testing of the Care Dependency Scale. J Adv Nurs 31, 944-952.

44. Dijkstra A, Coleman M, Tomas C, et al. (2003) Cross-cultural psychometric testing of the Care Dependency Scale with data. J Adv Nurs 43, 181-187.

45. Dijkstra A, Tiesinga LJ, Plantinga L, et al. (2005) Diagnostic accuracy of the Care Dependency Scale. J Adv Nurs 50, 410-416.

46. Twisk JWR (2010) Inleiding in de toegepaste biostatistiek (Introduction to Applied Biostatistics). Amsterdam: Reed Business.

47. Tannen A, Schutz T, Nie van NC, et al. (2008) Mangelernährung in deutschen Pflegeheimen und Krankenhäusern Pflegebedarf und pflegerische Versorgung (Malnutrition in German nursing homes and hospitals - care dependency and nursing interventions). Aktuelle Ernährungsmedizin 33, $177-183$

48. Tannen A \& Lohrmann C (2012) Malnutrition in Austrian hospital patients. Prevalence, risk factors, nursing interventions, and quality indicators: a descriptive multicentre study. $J A d v$ Nurs 69, 1840-1849.

49. Colín-Ramírez E, Orea-Tajeda A, Castillo-Martínez L, et al. (2011) Malnutrition syndrome, but not body mass index, is associated to worse prognosis in heart failure patients. Clin Nutr 30, 753-758.

50. Teh R, Wham C, Kerse N, et al. (2010) How is the risk of undernutrition associated with cardiovascular disease among individuals of advanced age? J Nutr Health Aging 14, 737-743

51. Suominen M, Muurinen S, Routasalo P, et al. (2005) Malnutrition and associated factors among aged residents in all nursing homes in Helsinki. Eur J Clin Nutr 59, 578-583.

52. Hickson M (2006) Malnutrition and ageing. Postgrad Med J 82, 2-8.

53. Meesterberends $\mathrm{E}$, Halfens $\mathrm{R}$, Spreeuwenberg $\mathrm{M}$, et al. (2013) Do patients in Dutch nursing homes have more pressure ulcers than patients in German nursing homes? A prospective multi-centre cohort study. JAMDA 14, 605-610. 